\title{
MUDANÇAS MORFOLÓGICAS DOS TESTÍCULOS DE CURIMBATÁ PROCHILODUS SCROFA (STEINDACHNER) (TELEOSTEI, PROCHILODONTIDAE), SUBMETIDO À INDUÇÃO HORMONAL
}

\author{
Emico Tahira Kavamoto ${ }^{1}$ \\ Massuka Yamane Narahara ${ }^{1}$ \\ Elaine Fender de Andrade-Talmelli ${ }^{1}$
}

\begin{abstract}
Morphological CHANGES OF THE TESTES OF THE CURIMBATÁ, PROCHILODUS SCROFA (STEINDACHNER), UNDER HORMONAL STIMULATION. This study concerns the morphological changes of the testes of "curimbatá", Prochilodus scrofa (Steindachner, 1881 ) at the beginning of sperm production, before and after the hormonal injections. We examined 25 three year old males that were reared in tanks at the Experimental Fish and Frog Culturing Station of Pindamonhangaba of the Fisheries Institute of São Paulo. The testes were sampled at the start of sperm production, after the first hormone injection ( $5 \mathrm{IU} / \mathrm{g}$ for weight of $\mathrm{hCG}$ ), and 14 days before and after a second injection. Testicle fragments of these specimens were fixed and embedded in historesin. At the beginning of sperm production, the milky-white gonad showed consistent superficial vascularization, exceeding thick sperm under light pressure. Microscopically, the presence of spermatogonia, many spermatocytes, spermatids and some tubules with spermatozoa were conspicuous. After the first hormonal dose, the gonads increased in volume, occupying most of the abdominal cavity superficial blood irrigation was evident, and sperm flowed easily out of the genital pore. Many spermatozoa were observed in the histology sections, along with spermatocytes and spermatids, within the lumen of the seminal tubules. After 14 days, the testes exhibited decreased volume and pink-white coloration. Light microscopy revealed few spermatozoa and disarrangement of the structures forming the seminal tubules. After the second hCG dose, the testes again increased in volume, occupying most of the abdominal cavity. Some tubules were filled with spermatozoa whereas others showed reduced numbers of this cellular type.
\end{abstract}

KEY WORDS. Prochilodus scrofa, fish, testes, morphology, hormonal stimulation

O presente estudo tem como objetivo descrever as características macro e microscópicas dos testículos de curimbatás submetidos à ação hormonal. Observouse que reprodutores de curimbatá Prochilodus scrofa (Steindachner, 1881), mantidos em condições de confinamento, apresentam no início do período de espermiação, pequeno volume de material espermático viscoso. Segundo KAVAMOTO et al. (1996), a qualidade e a quantidade do sêmen podem ser visivelmente aumentadas através da utilização de hormônios apropriados.

1) Divisão de Pesca Interior, Instituto de Pesca, CPA/SAA. Avenida Francisco Matarazzo 455, 05031-900 São Paulo, Brasil.

Revta bras. Zool. 15 (1): 109 - 115, 1998 
Experimentos de indução hormonal em machos foram desenvolvidos por TAKASHIMA et al. (1984); COURTOIS et al. (1986); SAAD \& BILlARD (1987); BILlard et al. (1989), em trabalhos com Cyprinus carpio; por KoBAYASH et al. (1986), com Carassius auratus; por CIERESZKo et al. (1993), com yellow perch e por OHTA \& IZAWA (1996), com Anguilla japonica. Todavia, pesquisas específicas relacionadas à ação de hormônios na maturação final das gônadas de machos de espécies autóctones não foram encontradas na literatura pertinente, o que motivou a elaboração desse trabalho.

\section{MATERIAL E MÉTODOS}

Para o desenvolvimento deste trabalho foram utilizados 25 exemplares de curimbatá Prochilodus scrofa, de três anos de idade, durante o período reprodutivo de 1991 e 1992, na Estação Experimental de Piscicultura e Ranicultura de Pindamonhangaba, Instituto de Pesca, São Paulo.

A descrição anatômica e a observação das características morfológicas dos testículos foram realizadas, no início da espermiação, após a aplicação da primeira dose de hCG (5 UI/g peso) e decorridos catorze dias, antes e após a aplicação da segunda dose hormonal; sendo que após a primeira dose hormonal, foi colhido sêmen de cada reprodutor, por compressão do abdômen no sentido antero-posterior.

Através de incisão longitudinal na região ventral de cada indivíduo, a gônada foi exposta e foram realizadas observações quanto ao volume, forma, coloração e vascularização superficial. Em seguida, fragmentos de cerca de $1 \mathrm{~cm}$ de espessura foram coletados da porção média dos testículos e fixados por 24 horas em formol a $10 \%$ tamponado e neutralizado; posteriormente, desidratados com banhos de 15 minutos cada, em soluções alcóolicas de concentrações crescentes de 70 a $95^{\circ} \mathrm{GL}$. Em seguida foram transferidos para uma mistura de $50 \%$ de resina básica (Historesin LKB) e $50 \%$ álcool $95^{\circ} \mathrm{GL}$, permanecendo neste meio por uma hora. A inclusão foi realizada em $15 \mathrm{ml}$ de resina básica acrescido de $1 \mathrm{ml}$ de endurecedor. Os cortes de $2 \mu \mathrm{m}$ de espessura foram obtidos em micrótomo automático com auxílio de navalha de vidro e em seguida, corados com Hematoxilina e Eosina (HE), utilizando-se Hematoxilina de GILL.

\section{RESULTADOS}

Os testículos de $P$. scrofa são estruturas pares, alongadas e cilíndricas que se situam na cavidade abdominal, ventralmente ao rim, ventro-lateralmente à vesícula gasosa e dorsalmente ao tubo digestivo; apresentam-se livres na porção anterior e média, porém, unem-se no terço posterior formando um ducto espermático comum que se abre ao meio externo através da papíla genital, por onde o sêmen é eliminado. Microscopicamente, apresentam-se revestidos por uma cápsula de tecido conjuntivo e contém, no seu interior, túbulos seminíferos separados entre sí por fina camada de tecido conjuntivo rico em vasos sanguíneos.

As células da linhagem espermatogênica foram descritas com base nas características microscópicas e divididas em quatro fases de desenvolvimento: 
Espermatogônias: são as maiores células encontradas, com limite celular bem definido. Apresentam núcleo esferoidal de localização central com um nucléolo. O citoplasma é abundante, com pouca afinidade por corantes. Dispõem-se isoladamente junto à parede interna dos túbulos e não se organizam em cistos.

Espermatócitos primários: apresentam-se agrupados em cistos e são células esferoidais, menores que as espermatogônias. O núcleo é volumoso em relação ao citoplasma e o nucléolo normalmente não é visível. O citoplasma é claro e de limites pouco precisos.

Espermatócitos secundários: são células menores que as anteriores, possuem forma arredondada, núcleo central, sem nucléolo evidente e com citoplasma reduzido.

Espermátides: os espermatócitos secundários dividem-se dando origem às espermátides e dentro de cada cisto ocorre o processo de espermiogênese, que é a transformação de espermátides em espermatozóides. São facilmente reconhecidas por serem as menores células arredondadas encontradas dentro de cistos, com forte afinidade por corantes básicos.

Espermatozóides: São as menores células germinativas presentes no testículo, apresentando cauda pouco visível e se encontram normalmente livres no lúmen dos túbulos seminíferos.

No início da espermiação, os testículos de consistência firme apresentam-se volumosos, de coloração branco-leitosa (opaca) e na sua superfície são evidentes alguns vasos sanguíneos; sob leve compressão na região ventral, há eliminação de sêmen espesso (viscoso). Microscopicamente, apresentam túbulos contendo espermatogônias, cistos com espermatócitos primários, espermatócitos secundários, espermátides, espermatozóides e alguns espermatozóides livres no lúmen (Fig. la). Após a aplicação da primeira dose hormonal, os testículos aumentam consideravelmente em peso e volume, ocupando quase toda a cavidade abdominal e apresentam irrigação sanguínea superficial proeminente com finas ramificações. O sêmen flui facilmente pela abertura genital. Pela observação microscópica dos cortes transversais nota-se que o lúmen fica repleto de espermatozóides (Fig. 1b), embora ainda sejam observados cistos contendo células em diferentes fases de desenvolvimento (espermatócitos e espermátides). Catorze dias após a primeira dose hormonal, os testículos apresentam redução em peso e volume, coloração branco-rosada e os vasos sanguíneos congestos. Pelo exame microscópico verifica-se certa desorganização na estrutura tubular e no lúmen, são visualizados poucos espermatozóides e na parede cistos contendo espermatócitos e espermátides (Fig. 2a). Após a aplicação da segunda dose de hCG, os testículos aumentam novamente de volume e pela avaliação histológica nota-se redução no número de cistos de espermatócitos e de espermátides e a presença de túbulos repletos de espermatozóides (Fig. 2b), embora outros apresentem-se com poucos espermatozóides.

\section{DISCUSSÃO}

Os testículos de curimbatá Prochilodus scrofa, como na maioria dos teleósteos, são órgãos pares, livres nas porções anterior e média, unidos no terço posterior 
e formando um único ducto espermático; apresentam superfície externa lisa e sofrem modificações no volume, forma e coloração durante o desenvolvimento gonadal (ALEXANDRINO et al. 1985).

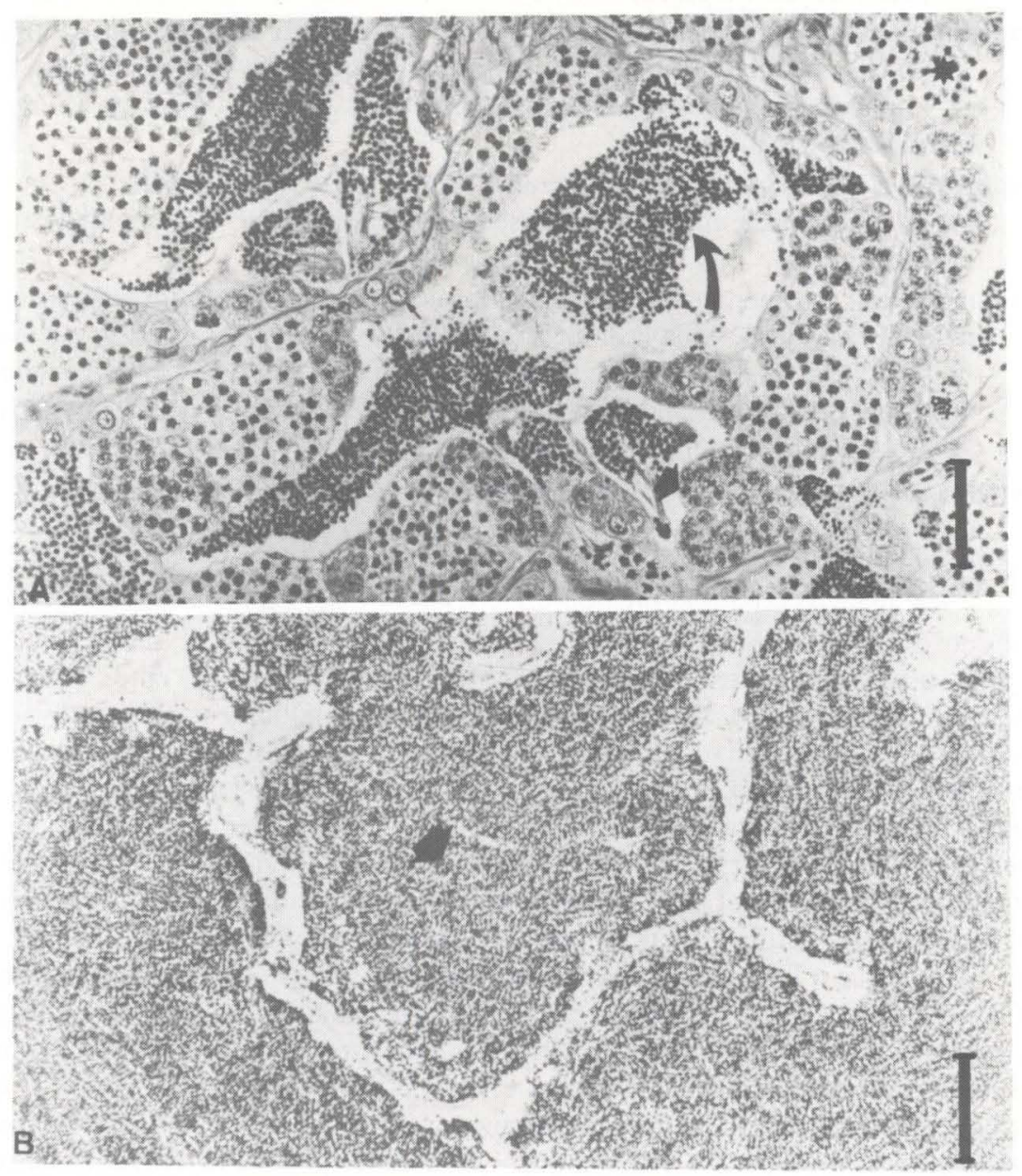

Fig. 1. Corte transversal do testículo de curimbatá, Prochilodus scrofa: a) no início do período de espermiação - espermatogônias (asterisco), cistos contendo espermatócitos (seta curta), espermátides (estrela) e espermatozóides no lúmen (seta longa) $(\mathrm{H} / \mathrm{E}) ; \mathrm{b}$ ) após a primeria dose hormonal - túbulos repletos de espermatozóides (seta grossa) $(H / E)$. Barra=0,02mm.

No início do periodo reprodutivo, os testículos são de coloração branco-leitosa e apresentam-se bem desenvolvidos. Ao exame microscópico apresentam-se compostos por numerosos túbulos contendo cistos, sendo que cada cisto abriga células da linhagem espermatogênica na mesma fase de desenvolvimento. Os 

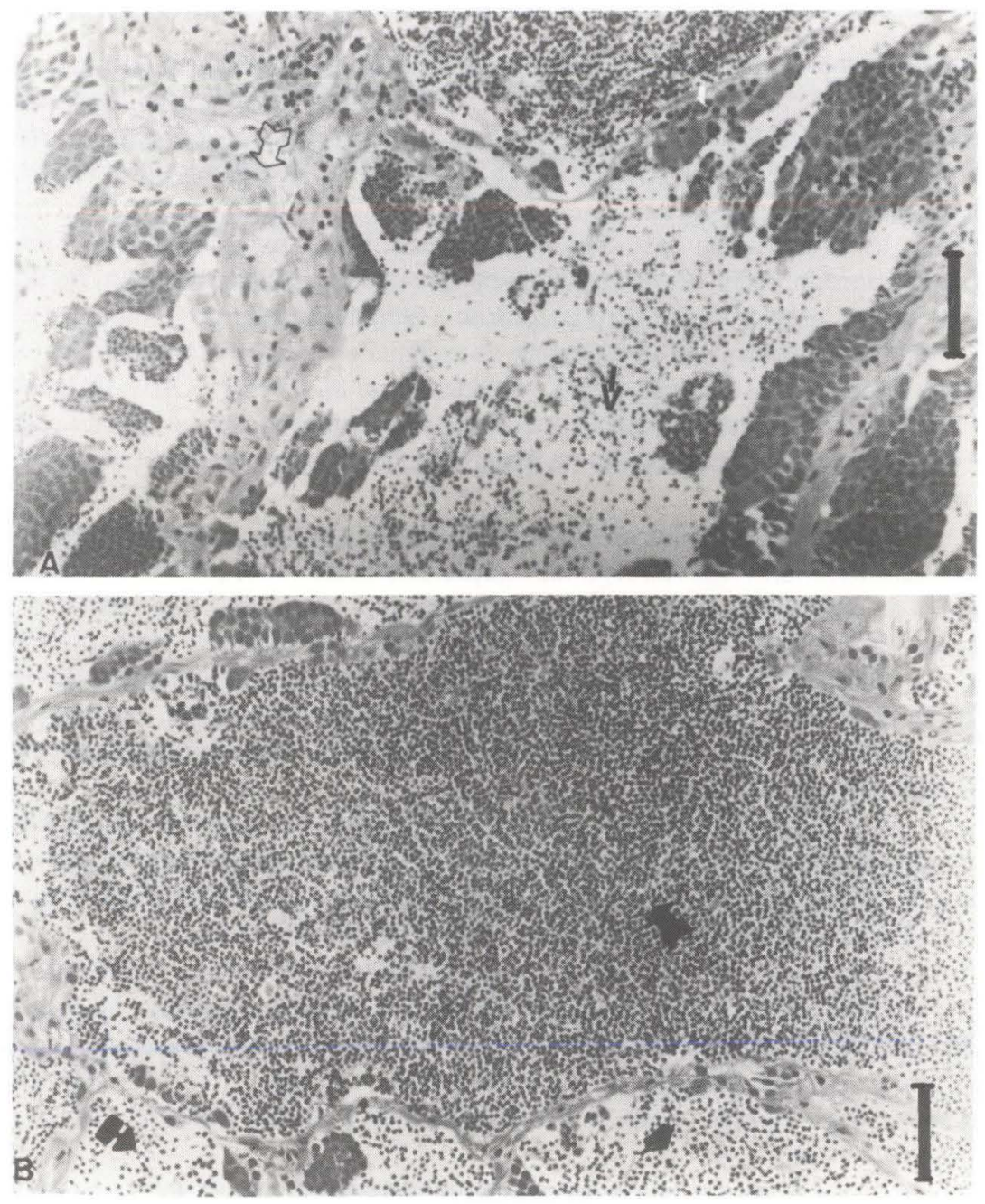

Fig. 2. Corte transversal do testiculo de curimbatá, Prochilodus scrofa: a) antes da segunda dose de hCG - poucos espermatozóides (seta grossa) espermatogônia (seta longa), espermatócitos (seta curta), desorganização dos túbulos seminíferos (/E); b) após a segunda injeção hormonal - túbulos com grande quantidade de espermatozóides (seta grossa) e outros com poucos (círculo) $(\mathrm{H} / \mathrm{E})$. Barra=0,02 mm.

espermatozóides resultantes da espermiogênese são liberados para o lúmen dos túbulos seminíferos. Segundo ALEXANDRINO et al. (1985), a presença de espermatozóides nas paredes dos túbulos, indica que énecessário existir certo grau de maturação nestas células, antes de serem liberadas para o lúmen. As alterações morfoestruturais das células germinativas, evidenciam modificações gradativas, sendo os espermatozóides o tipo celular mais abundante no estádio final de maturação. O mesmo autor ainda descreve que no estádio final de Maturação, o curimbatá 
deixa fluir, sob leve pressão no abdômen ou ainda somente pela manipulação, um líquido espesso e leitoso. KAVAMOTO et al. (1989), confirmaram estas informações observando amostras de sêmen colhidas de peixes que não haviam recebido tratamento hormonal (KAVAMOTO et al. 1996). Entretanto, os exemplares que receberam injeção hormonal apresentam sêmen mais fluido e grande quantidade de espermatozóides livres no lúmen dos túbulos seminíferos. Este fato, provavelmente pode estar relacionado, além do desenvolvimento natural da gônada, ao efeito do hormônio sobre a espermiogênese, aumentando a hidratação seminal (KOBAYASHI et al. 1986) e transformando rapidamente as espermátides em espermatozóides. Da mesma forma, BILlARD et al. (1983); CIERESZKO et al. (1993) e OHTA \& IZAWA (1996), verificaram que os machos induzidos à espermiação, através de aplicação hormonal, apresentaram aumento na quantidade de espermatozóides e no volume seminal.

A desorganização dos túbulos seminíferos e a diminuição de espermatozóides livres observadas antes da segunda injeção, devem ser conseqüência da extrusão forçada do sêmen e da queda da ação da primeira dose hormonal, concordando com as observações feitas por SAAD \& BILLARD (1987), que também verificaram em carpas, o desaparecimento dos espermatozóides no trato genital simultâneamente à diminuição de gonadotrofina circulante. Esta suposição ainda pode ser reforçada pela observação de que os peixes que receberam a segunda dose hormonal passaram a produzir sêmen novamente.

Outro fato evidente é que a gonadotrofina coriônica humana (hCG) não atuou somente na espermiogênese, mas também na fase final da espermatogênese, pois os cistos de espermatócitos e espermátides presentes antes da segunda injeção desaparecem dando lugar à grande quantidade de espermatozóides livres.

De acordo com TAKASHIMA et al. (1984) e CourToIs et al. (1986) a espermiação contínua pode ser obtida através de repetidas aplicações hormonais sendo que, SAAD \& BILLARD (1987), também trabalhando com Cyprinus carpio, verificaram que uma aplicação hormonal por semana durante nove meses provocou mobilização do estoque testicular produzindo sêmen de boa qualidade durante a maior parte do ano.

As informações obtidas com esse estudo, permitem comprovar histológicamente as afirmações de KaVAmoto et al. (1996) de que, os machos de P. scrofa com três anos de idade, podem ser utilizados como reprodutores por duas vezes durante um mesmo ciclo reprodutivo.

AGRADECIMENTOS. As autoras agradecem a Cleide S.R. Mainardes-Pinto, Chefe da Estação Experimental de Piscicultura e Ranicultura de Pindamonhangaba e aos funcionários de apoio à pesquisa pertencentes a esta Estação, pela colaboração na coleta de dados. Agradecem também, ao técnico José Plaza pela confecção das lâminas histológicas.

\section{REFERÊNCIAS BIBLIOGRÁFICAS}

Alexandrino, A.C.; M.T. Phan \& E.F.G. Pinheiro. 1985. Caracterização macroscópica e microscópica das gônadas do curimbatá, Prochilodus scrofa (Stein- 
dachner, 1881), durante o ciclo reprodutivo. Bolm. Zool. Univ. São Paulo 9: 159-175.

BILLARD, R.; J.P. CHOISIS \& P. REINAUD. 1983. Stimulation of spermiation in carp in response to LH-RH and D-Ala ${ }^{6}-\mathrm{LH}-\mathrm{RH}$ ethylamide. Aquaculture 35 (2): 173-176.

Billard, R; K. Bieniarz; W. Popek; P. Epler \& A. SAad. 1989. Observations on a possible pherormonal stimulation of milt production in carp (Cyprinus carpio L.). Aquaculture 77 (4): 387-392.

COURTOIS, F.; F. TAKASHIMA \& D.R. BILlard. 1986. Stimulation of spermiation following repeated injection of carp pituitary homogenates in the carp. Bull. Jap. Soc. Sci. Fish 52 (6): 995-997.

Ciereszko, A.; L. Ramseyer \& K. Dabrowski. 1996. Cryopreservation of Yellow Perch semen. Progressive Fish-Culturist 55: 261-264.

Kavamoto, E.T.; W.F. Silveira; H.M. Godinho \& E. Romagosa. 1989. Fertilização em Prochilodus scrofa, Steindachner, 1881, com sêmen criopreservado em nitrogênio líquido. Bol. Inst. Pesca 16 (1): 29-36.

Kavamoto, E.T.; E.M. FerRaZ; E.F. DE ANdRade-Talmelli; C.S.R. MainaRDes-Pinto; E. Romagosa; M.Y. Narahara; R.C. Barnabe \& B.E.S. DE CAMPos. 1996. Estimulação da espermiação em curimbatá Prochilodus scrofa (Steindachner) através de aplicações de hCG (Osteichthyes, Characiformes, Prochilodontidae). Revta bras. Zool. 13 (1): 27-38.

Kobayashi, M.; K.L. Aida \& I. HanYU. 1986. Effects of on milt amount and plasma level of steroid hormones in male goldfish. Bull. Jap. Soc. Sci. Fish. 52 (4): 755-756.

OHTA, H. \& T. IZAWA. 1996. Diluent for cool storange of the japanese eel (Anguilla japonica) spermatozoa. Aquaculture 142: 107-118.

SAAD, A. \& R. BILLARD. 1987. Spermatozoa production and volume of semen collected after hormonal stimulation in the carp, Cyprinus carpio. Aquaculture, The Netherlands, 65 (1): 67-77.

Takashima, F.; C. Weill; R. Billard; L.W. Crim \& A. Fostier. 1984. Stimulation of spermiation LH-RH analogue in carp. Bull. Jap. Soc. Sci. Fish. 50 (8): 1329-1339.

Recebido em 22.VIII.1996; aceito em 27.II.1998. 